Colloque C2, supp1. au Journal de Physique II, Vol. 1, septembre 1991

\title{
TITANOCENE-DICHLORIDE AS A METALORGANIC SOURCE FOR TITANIUM CARBIDE
}

\author{
J. SLIFIRSKI*, G. HUCHET ${ }^{*}$ and F. TEYSSANDIER* * \\ * CNRS Institut de Science et de Génie des Matériaux et \\ Procédés, Université, avenue de vilileneuve, \\ F-66860 Perpignan cedex, France \\ **Etablissement Technique Central de I'Armement, 16 bis avenue \\ Prieur de la côte d'or, F-94114 Arceuil cedex, France
}

\begin{abstract}
The use of titanocene-dichloride $\left(\mathrm{Cp}_{2} \mathrm{TiCl}_{2}\right)$ as a metalorganic precursor for $\mathrm{TiC}$ coating provides layers of very different quality according to its temperature of vaporization in a cold wall CVD reactor. The deposits observed by SEM and characterized by EPMA are related to the experimental procedure. The thermal behavior of the precursor investigated by thermogravimetry (TG), thermogravimetry coupled with differential thermal analysis (TG-DTA) and mass spectroscopy (MS) is used to determine the structural state of $\mathrm{Cp}_{2} \mathrm{TiCl}_{2}$ active from a $\mathrm{CVD}$ point of view.
\end{abstract}

\section{INTRODUCTION}

Due to its refractory nature $\left(\mathrm{mp}=3067^{\circ} \mathrm{C}\right)$, hardness, corrosion resistance, low friction behavior and high abrasion resistance, titanium carbide has been used as wear protective coating for many years. Initially deposited on cemented carbide cutting tools or inserts, its application field has considerably increased and a great variety of substrates are now industrially treated. In particular, many kind of steels are coated to provide interesting surface properties.

The initial gas mixture of the industrial process is composed of hydrogen, methane and titanium tetrachloride. The high temperatures $\left(T>950{ }^{\circ} \mathrm{C}\right.$ ) required to obtain satisfactory deposition rates are responsible for many drawbacks such as: residual stresses, grain growth of the substrate structure, stabilization of the austenite structure in the case of steel substrates, decarburization of carbon-containing substrates and, more generally, solid state modifications or interactions with the substrate.

In order to overcome these problems, it is worth lowering the process temperature, which can be achieved by the use of less stable precursors such as metalorganic compounds.

\section{PREVIOUS WORK ON MOCVD OF TITANIUM BASED COMPOUNDS.}

Deposits generally carried out at temperature below $500^{\circ} \mathrm{C}$ lead to amorphous titanium- based materials even if $\mathrm{X}$-ray diffraction reveals the presence of very small crystals for specific experimental parameters. Metalorganic chemical vapor deposition of titanium rich deposits $(\mathrm{Ti}(\mathrm{C}, \mathrm{N}, \mathrm{H})$ ) were obtained by Morancho and al. [1-2] in the temperature range $370-520^{\circ} \mathrm{C}$ from Tris-(2,2'-bipyridine). Tetraneopentyltitanium $\left(\mathrm{Ti}\left[\mathrm{CH}_{2} \mathrm{C}\left(\mathrm{CH}_{3}\right)_{3}\right]_{4}\right)$ has also been used successfully in a slightly lower temperature range $\left(150-300^{\circ} \mathrm{C}\right)[3-4]$ to deposit $(\mathrm{Ti}, \mathrm{C}, \mathrm{H})$ materials. In both cases, pressures are below $10^{-5}$ torr. More recently [5], amorphous $\left(300^{\circ} \mathrm{C}\right)$ and crystalline $\left(400-580^{\circ} \mathrm{C}\right)$ 
TiN have been deposited under 0.3 Torr from an initial mixture of tetradimethylaminotitanium $\left(\mathrm{Ti}\left(\mathrm{N}\left(\mathrm{CH}_{3}\right)_{2}\right)_{4}\right)$ and $\mathrm{NH}_{3}$.

In all cases very low deposition rates are observed (lower than $0.4 \mu \mathrm{m} / \mathrm{h}$ ). Furthermore, these metalorganic compounds are very sensitive to oxygen and moisture and great care must be taken to avoid pollution.

\section{EXPERIMENTS}

Experiments were carried out in a classical cold wall reactor. The polished steel substrate is heated by an r.f coil. Its temperature is adjusted by a chromel-alumel thermocouple inserted in a hole drilled in the back face. The crucible is heated by a resistor wrapped around it and equipped with a thermocouple. In order to prevent extra heating of the metalorganic compound by radiation from the substrate, the receiving crucible is covered by a lid with a hole drilled in the middle (diam. $=1 \mathrm{~mm}$ ). The carrier gas flowrate (hydrogen) is controlled by means of a mass flowmeter and the distance between the crucible and the substrate is $40 \mathrm{~mm}$.

The following experimental procedure is used. The substrate is first heated to the deposition temperature under hydrogen flow, then two ramps of temperature are successively applied to the receiving crucible: $10 \% \mathrm{~min}$ from $25^{\circ} \mathrm{C}$ to $200^{\circ} \mathrm{C}$ and $1 \% \mathrm{~min}$ from $200^{\circ} \mathrm{C}$ to the terminal temperature which is held for 5 hours. When the substrate temperature and the terminal temperature of the crucible are respectively $\mathrm{Ts}=750^{\circ} \mathrm{C}$ and $\mathrm{Tp}=400{ }^{\circ} \mathrm{C}$ the deposit observed on a polished cross-section presents two layers of different thickness as shown in figure 1 [6].The layer adjacent to the substrate is $6 \mu \mathrm{m}$ thick and composed of many sublayers with a mean thickness lower than $0.5 \mu \mathrm{m}$. The second one is thicker $(e=10 \mu \mathrm{m})$ and homogeneous in composition. Both layers present a high carbon content ( near 60 at\%) as measured by EPMA, due to an initial molecule including two $\mathrm{Cp}$ groups. But the main difference concerns the oxygen and chlorine amounts. The first layer includes almost no chlorine but the oxygen content, depending on the sample, ranges between 10 and 20 at\%. The oxygen concentration in the homogeneous layer does not exceed 2 at $\%$ and the chlorine content is about 1 at\%. Two typical compositions are given as an indication: 1) $\mathrm{Ti}_{0.34} \mathrm{C}_{0.57} \mathrm{O}_{0.09}$ 2) $\mathrm{Ti}_{0.38} \mathrm{C}_{0.59} \mathrm{O}_{0.02} \mathrm{Cl}_{0.01}$. The composition of layer 1 is calculated as a percentage, though the total of the mass fractions obtained after the ZAF corrections is significantly lower than one in every case. This phenomenon probably results from the inhomogeneities of the layer as observed by SEM.

The same experiment carried out at $\mathrm{T} p=280^{\circ} \mathrm{C}$ provides only a very thin layer $(\approx 1 \mu \mathrm{m})$ which has not been analysed.

A modification of the experimental procedure allows the suppression of the layer composed of many sublayers. The crucible is heated to $300^{\circ} \mathrm{C}$ with the two ramps already mentioned but the temperature of the substrate is maintained during this process at a low temperature $\left(250^{\circ} \mathrm{C}\right)$ which inhibits surface reactions and prevents condensation of the metalorganic compound. Then the substrate temperature is raised to $750^{\circ} \mathrm{C}$ for 5 hours. Only the type 2 layer is obtained with a thickness of $15 \mu \mathrm{m}$ figure 2 . It is worth mentioning that such a thickness is perhaps reached in less than 5 hours. As a matter of fact previous experiments [6] have shown that a $7 \mu \mathrm{m}$ thick layer can be deposited within $50 \mathrm{~min}$ at $700^{\circ} \mathrm{C}$, which corresponds to a deposition rate higher than $8 \mu \mathrm{m} / \mathrm{h}$. 


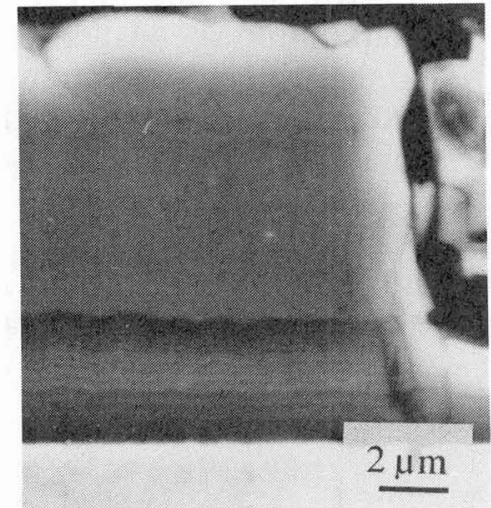

FIGURE 1: Two types of TiC layer.

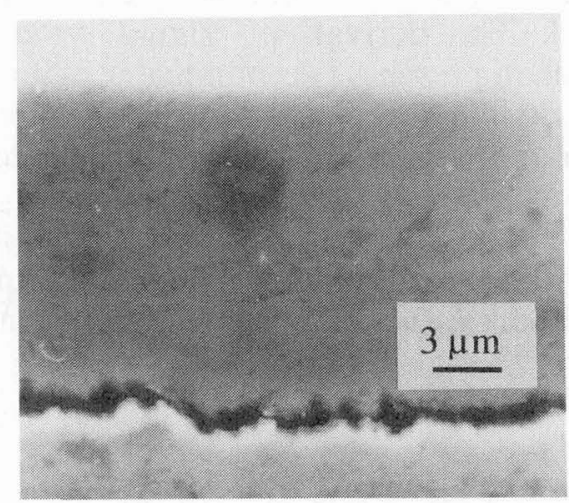

FIGURE 2: $15 \mu \mathrm{m}$ homogeneous TiC layer.

These experiments show the influence of the vaporization temperature of $\mathrm{Cp}_{2} \mathrm{TiCl}_{2}$. We will now try to understand the structural modifications thermally induced in the metalorganic precursor that are responsible for these various type of coatings.

\section{THERMAL ANALYSIS}

The thermal behavior of $\mathrm{Cp}_{2} \mathrm{TiCl}_{2}$ was first investigated with thermogravimetry (T.G) and then with thermogravimetry coupled with differential thermal analysis (DTA)

\section{THERMOGRAVIMETRY (Perkin Elmer TGS2)}

$\mathrm{Cp}_{2} \mathrm{TiCl}_{2}$ was heated at different rates from 5 to $20 \%$ min under a nitrogen flow. The curve presented in figure 3 obtained at $15 \% \mathrm{~min}$ is typical of the thermal behavior of the compound and shows four main domains :

- up to $190^{\circ} \mathrm{C}$ no weight loss is observed,

- from $190^{\circ} \mathrm{C}$ to $310^{\circ} \mathrm{C}, 60$ weight $\%$ of the product is lost at a fast rate,

- from $310^{\circ} \mathrm{C}$ to $680^{\circ} \mathrm{C}$, about 24 weight $\%$ is lost,

- above $680^{\circ} \mathrm{C}$ no appreciable modification can be detected.

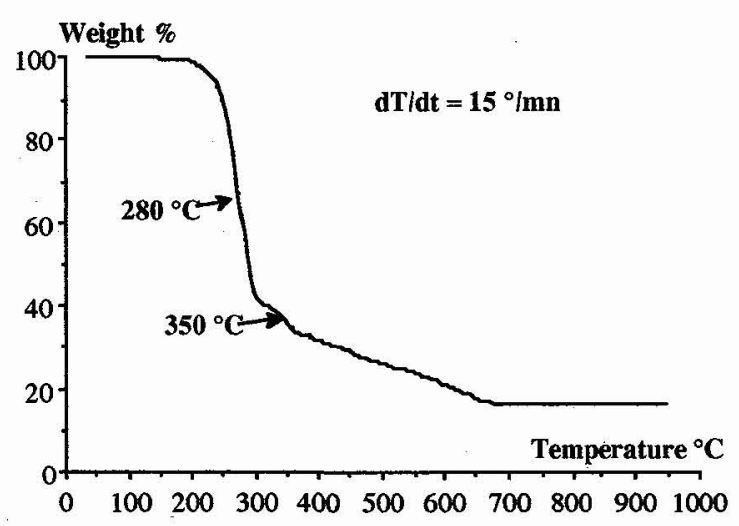

FIGURE 3: Thermogravimetry of $\mathrm{Cp}_{2} \mathrm{TiCl}_{2}$ with a temperature ramp of $15 \% \mathrm{~min}$. 
The total weight loss of the sample is $84 \%$. From this curve two main phenomena are observed. The derivative signal which indicates the maximum speed for each phenomenon presents two minima at 280 and $350^{\circ} \mathrm{C}$. Due to thermal and mass transfer in the crucible the temperature corresponding to these maxima are function of the applied ramp: higher rates shift the peaks towards high temperatures.

These values recorded for different ramps are plotted in figure 4 and allow the extrapolation of the temperatures corresponding to the static transformation: $258{ }^{\circ} \mathrm{C}$ and $290^{\circ} \mathrm{C}$.

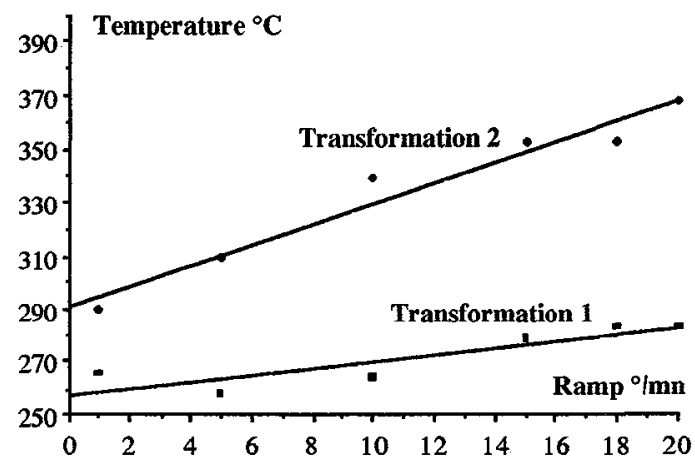

FIGURE 4: Variation of the temperature corresponding to the maximum rate of the three transformations observed for $\mathrm{Cp}_{2} \mathrm{TiCl}_{2}$ and plotted as a function of the ramp.

$290{ }^{\circ} \mathrm{C}$ is the established melting point from the literature but $258{ }^{\circ} \mathrm{C}$ does not correspond to any physical phenomenon known about $\mathrm{Cp}_{2} \mathrm{TiCl}_{2}$. In order to confirm these results experiments were undertaken in a TG-DTA device.

THERMOGRAVIMETRY coupled with DIFFERENTIAL THERMAL ANALYSIS.(Setaram DT-TGA92)

The metalorganic compound is disposed in an alumina crucible hanging from the beam of a micro-balance and located in the middle of a vertical furnace. An identical crucible filled with a non-reactive compound is heated together. The heat flow is monitored with thermocouples which equip both crucibles. The device was used either with nitrogen or hydrogen but the nature of the gas had no significant influence on the spectra. The heating rate was set at the lowest available value: $1 \% \mathrm{~min}$. The mass loss and the heat flow recorded from 200 to $300^{\circ} \mathrm{C}$ are presented in figure 5 .

The differential thermogravimetric signal presents two main peaks at 270 and $285^{\circ} \mathrm{C}$. (We must also mention the additional peak at $291{ }^{\circ} \mathrm{C}$ which is reproducible and therefore seems to be meaningful). Two endothermic peaks are observed at the same temperatures. These values plotted in figure 3 are in good agreement with the previous TG measurements and we may reasonably assume from these measurements that the second event is the melting of $\mathrm{Cp}_{2} \mathrm{TiCl}_{2}$. 


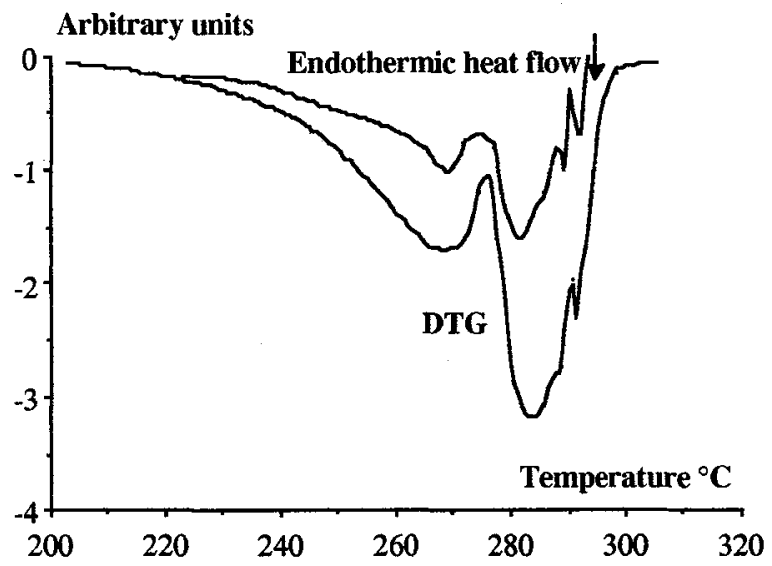

FIGURE 5: Comparison between the heat flow and the differential thermogravimetric signal of $\mathrm{Cp}_{2} \mathrm{TiCl}_{2}$ heated at a rate of $1 \% \mathrm{~min}$ from 200 to $300^{\circ} \mathrm{C}$.

Additional experiments were performed to determine the thermal behavior of the metalorganic compound under isothermal conditions. The mass loss is then recorded as a function of time at a constant temperature which is imposed very rapidly $(120 \% \mathrm{~min})$ without any overshoot. The mass fraction of the residue is plotted in figure 6 against the level temperature.

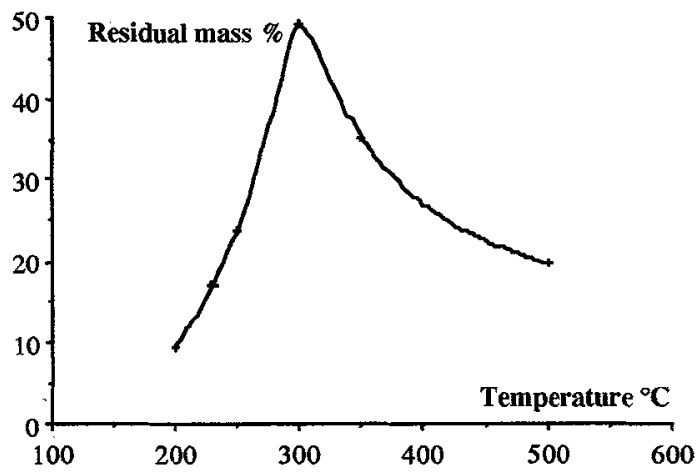

FIGURE 6: Residual mass percentage as a function of the temperature of the isothermal treatment.

The results obtained below $200{ }^{\circ} \mathrm{C}$ are not plotted because the sample was still losing mass after 8 hours, which was the duration devoted to the experiment. The increasing mass fraction of the residue from $\approx 190$ to $300^{\circ} \mathrm{C}$ is a proof of the transformation of $\mathrm{Cp}_{2} \mathrm{TiCl}_{2}$ below the melting point. The elemental composition of the remaining product at temperatures below $290^{\circ} \mathrm{C}$, determined by chemical analysis give the same composition as the starting compound. A decomposition would have formed byproducts of different volatility providing a composition of the residue different from $\mathrm{Cp}_{2} \mathrm{TiCl}_{2}$. We may then consider that a dimerization or a polymerization is the most 
probable type of transformation occurring between 190 and $290^{\circ} \mathrm{C}$. The slight variation of the molecular formula involved in the dimerization of such compounds remains within the uncertainty of the chemical analysis.

Above $300^{\circ} \mathrm{C}$ the residual mass fraction decreases, which is an indication of a decomposition process. The morphology of the residue depends very much on temperature: from 50 to $280^{\circ} \mathrm{C}$ it has the same appearance as the initial product which is red and well crystallized. When maintained at $280^{\circ} \mathrm{C}$ it turns progressively to black but still presents the same crystalline structure. Residues from $\mathrm{Cp}_{2} \mathrm{TiCl}_{2}$ heated above $300{ }^{\circ} \mathrm{C}$ look like solidified tar and are no longer soluble in toluene. The decomposition of $\mathrm{Cp}_{2} \mathrm{TiCl}_{2}$ above $300^{\circ} \mathrm{C}$ is confirmed by mass spectroscopy measurements.

\section{MASS SPECTROSCOPY}

Neutral species resulting from the vaporization and/or decomposition of $\mathrm{Cp}_{2} \mathrm{TiCl}_{2}$ are studied by means of a Finnigan Mat 8002 quadrupole spectrometer. The compound is introduced directly into the ionization chamber of the apparatus. Electron impact spectra using $70 \mathrm{eV}$ electrons were recorded at different temperatures of $\mathrm{Cp}_{2} \mathrm{TiCl}_{2}$ heated in situ at a rate of $12 \% \mathrm{~min}$. Two different spectra are observed. Below a transition temperature which is estimated at $310{ }^{\circ} \mathrm{C}$ the monomer $(\mathrm{m} / \mathrm{e} 248)$ and fragments resulting from electron impact are mainly observed. Above that transition temperature the importance of the low $\mathrm{m} / \mathrm{e}$ fragments increases rapidly and the occurrence of $\mathrm{HCl}$ $(\mathrm{m} / \mathrm{e} 36)$ reveals the decomposition of the molecule.
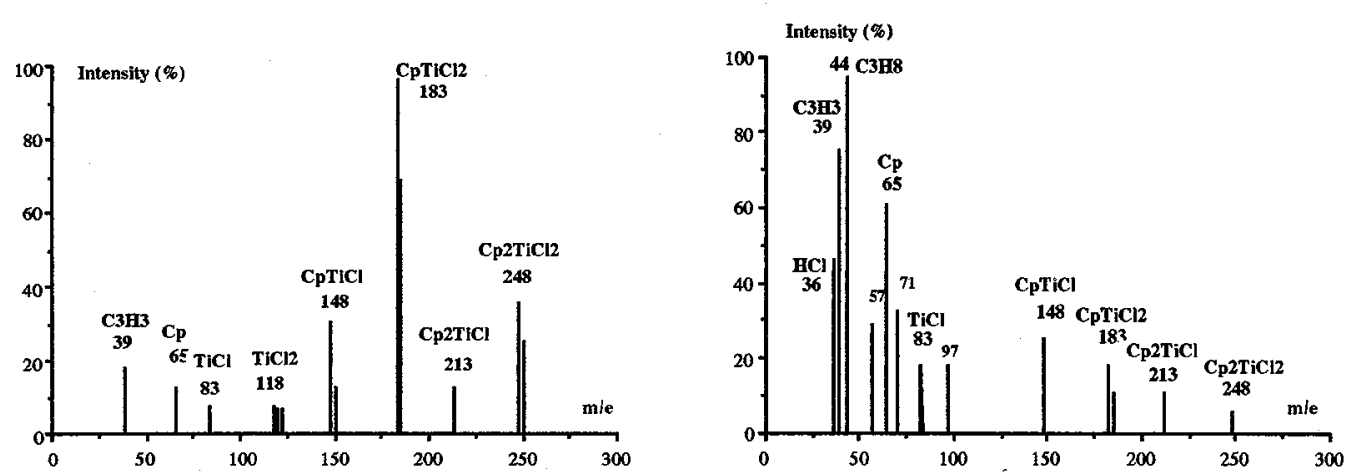

Mass spectrum of $\mathrm{Cp}_{2} \mathrm{TiCl}_{2}$ FIGURE 7: below $310^{\circ} \mathrm{C}$ FIGURE 8: above $310^{\circ} \mathrm{C}$

\section{CONCLUSION}

All these measurements provide a coherent set of information on the thermal behavior of $\mathrm{Cp}_{2} \mathrm{TiCl}_{2}$. It sublimates without any structural modification up to $190{ }^{\circ} \mathrm{C}$. In the temperature range $190-290{ }^{\circ} \mathrm{C}$ the sublimation is in competition with a phenomenon which increases the amount of the residue but does not fundamentally change the elemental composition. This structural modification is supposed to be a dimerization (or a polymerization). $290{ }^{\circ} \mathrm{C}$ may be the melting temperature of the monomer or the dimer as stated in the literature but this physical transformation is accompanied or immediately followed by a decomposition of the compound. This decomposition, which is kinetically controlled though the melting is only limited by heat transfer (in the absence of metastable equilibria), can account for the rather high slope of 
transformation 2 observed as a function of the heating rate in figure 4. From a CVD point of view the sublimation of the molecule and its subsequent decomposition in the thermal gradient layer in the vicinity of the substrate or the transfer in the gas phase of by-products (and probably also their transformation in the thermal gradient layer) resulting from the decomposition in the crucible are not at all equivalent. In the first case a coating of poor quality is obtained at a low deposition rate though the preliminary thermal decomposition provides at a higher growth rate a good quality layer.

\section{ACKOWLEDGEMENTS}

The authors are indebted to P.Cassoux, L.Valade and R.Choukroun from LCC (Toulouse) and R.Morancho, A.Reynes from ENSCT (Toulouse) for TG-DTA measurements and helpful discussions.

\section{REFERENCES}

/1/ Morancho R. , Constant G. , Ehrhardt J.J. , Thin solid film, 77 (1981) 155.

12/ Morancho R. , Petit J.A. , Dabosi F. , Constant G., J. Electrochem.Soc., 129,4 (1982) 854.

/3/ Kaloyeros A.E. , Hoffman M.P. , Williams W.S. , Thin Solid Films, 141 (1986) 237.

14/ Girolami G.S. , Jensen J.A., Pollina D.M., Williams W.S., Kaloyeros A.E. , Allocca C.M. ,

J. Am. Chem. Soc., 109 (1987) 1579.

15/ Ishihara K., Yamazaki K., Hamada H., Kamisako K., Tarui Y., Jpn.J.Appl.Phys., 29,10 (1990) 2103.

/6/ Huchet G., Teyssandier F.,

Proc. of the XI Intern. Conf. on CVD, Cullen G.W. , Spear K.E. (Eds), Seattle USA, (1990) 703. 